\title{
The Protective Influence of Mentoring on Adolescents' Substance Use: Direct and Indirect Pathways
}

\author{
Jean E. Rhodes and Ranjini Reddy \\ University of Massachusetts \\ Jean B. Grossman \\ Public/Private Ventures
}

\begin{abstract}
A conceptual model was tested in which mentoring relationships were hypothesized to reduce substance use both directly and indirectly through improvements in adolescents' self-perceptions and close relationships. The study included 928 young adolescents (M age = 12.25), all of whom applied to Big Brothers Big Sisters programs. The adolescents were randomly assigned to either the treatment or control group and administered questions at baseline and 18 months later. The hypothesized model was not substantiated particularly well with data from the entire sample but was strongly supported when it was estimated with a subgroup of youth who were in longerlasting relationships. Being matched for longer than 12 months had significant impacts on the frequency of substance use and on parental relationships. Consistent with our conceptual model, parental relationships mediated the relationship between mentoring and substance use. Implications of these findings for research and interventions are discussed.
\end{abstract}

Millions of American youth are engaged in schooland community-based mentoring programs, and by all accounts the popularity of this intervention strategy will continue to grow (Rhodes, 2002). Evaluations of volunteer mentoring programs provide evidence of positive influences on adolescent behavioral outcomes, including reductions in substance use (Aseltine, Dupre, \& Lamlein, 2000; Davidson \& Redner, 1988; LoSciuto, Rajala, Townsend, \& Taylor, 1996; McPartland \& Nettles, 1991; Ringwalt, Graham, Paschall, Flewelling, \& Brown, 1996) and improvements in their reactions to situations involving substance use (Taylor, LoSciuto, Fox, Hilbert, \& Sonkowsky, 1999). For example, a national evaluation of Big Brothers Big Sisters (BBBS) programs revealed that, in addition to better psychosocial and academic functioning, mentored youth were less likely than controls to start using alcohol and drugs (Grossman \& Tierney, 1998). These findings are particularly promising in light of the potentially devastating effects of substance use among adolescents (Hawkins, Catalano, \& Miller, 1992) and the heightened risk of many of the youth who are referred to mentoring programs. Nonetheless, basic questions remain regarding the underly-

This study was completed with the assistance of a grant from the William T. Grant Foundation. The authors also gratefully acknowledge the cooperation of Big Brothers Big Sisters of America.

Requests for reprints should be sent to Jean E. Rhodes, University of Massachusetts, Boston, Department of Psychology, 100 Morrissey Blvd., Boston, MA 02125.E-mail: jean.rhodes@umb.edu ing factors that mediate mentors' influence on use of drugs and alcohol over time. In this study, a conceptual model of mentoring and substance use is proposed and tested.

\section{Substance Use in Adolescence}

Recent epidemiological data evidences the widespread use of alcohol and other illicit substances among secondary school students. In their annual national survey, Johnston, O'Malley, and Bachman (2003) found, as early as eighth grade, $31 \%$ of youth have tried alcohol and $11 \%$ have become cigarette smokers. Moreover, in 2002, $17.7 \%$ of 8th graders and $34 \%$ of 10th graders reported using illicit drugs in the past year, up from $11.7 \%$ and $21 \%$ respectively in 1991 (Johnston et al., 2003; also see Weinberg, Rahdert, Colliver, \& Glantz, 1998).

Because mentoring programs tend to target youth who, by virtue of their family situation or other circumstances, are at greater than average risk for poor developmental outcomes (DuBois, Holloway, Cooper, \& Valentine, 2002; Rhodes, 2002), rates among youth in programs are likely to be even higher. For example, many mentoring programs (including most BBBS agencies) give preference to youth who have no more than one parent actively engaged in their life. Similarly, youth are often referred to mentoring programs in response to emerging psychosocial, behavioral, or aca- 
demic difficulties. Such difficulties, particularly in the context of poverty and family instability, are considered risk factors for later substance abuse (Sampson \& Laub, 1993; Zimmerman \& Schmeelk-Cone, 2003).

These trends in substance use and their negative personal and societal consequences highlight the need for a better understanding of both the risk and protective factors. A variety of theoretical approaches have been forwarded, ranging from theories that emphasize genetic and psychological vulnerabilities to those that focus on more contextual variables (for a review see Petraitis, Flay, \& Miller, 1995). Low self-worth, for example, has been demonstrated to be a risk factor for higher levels of usage among young adolescents (Miller, 1994; Rhodes, Gingiss, \& Smith, 1994; Richter, Brown, \& Mott, 1992) as have a broad array of other variables (Petraitis et al., 1995).

Central to most explanatory models, however, is an emphasis on peers and their role in shaping usage patterns (Barnes, 1990; Jessor \& Jessor, 1977). Peer substance use is considered to be one of the strongest predictors of adolescent substance use (Brook, Brook, Gordon, Whiteman, \& Cohen, 1990; Hawkins, Catalano, \& Miller, 1992; Newcomb \& Bentler, 1986) and previous research provides both cross-sectional and longitudinal support for this association (e.g., Curran, Stice, \& Chassin, 1997; Duncan, Duncan, \& Hops, 1994; Kandel \& Andrews, 1987). These research patterns are further replicated in epidemiological work that shows since 1992, patterns of adolescent alcohol use and friends' alcohol use have been fairly parallel (Johnston et al., 2001; Li, Duncan, \& Hops, 2001). In fact, it has been suggested that peer variables not only dominate the prediction of substance use but also mediate the effects of other variables (Oetting \& Beauvais, 1987). Oetting and Beauvais (1987) argued peers initiate youth into drugs, provide drugs, model drug-using behavior, and shape attitudes about drugs (also see Schulenberg et al., 1999).

Parental influence has also been found to play an important role in substance use patterns (Andrews, Hops, Ary, Tildesley, \& Harris, 1993). Numerous studies have found that the presence and quality of parental relationships strongly predicts adolescent usage patterns. Whereas conflictual relationships appear to heighten the risk for alcohol and drug use, closer relationships protect adolescents from substance use (e.g., Barnes, Farrell, \& Cairns, 1986; Barnes, Farrell, \& Windle, 1990; Bell, Forthun, \& Sun, 2000; Brook, Whiteman, \& Gordon, 1982; Brook, Whitman, Gordon, \& Brook, 1984; Farrell \& White, 1998; Hundleby \& Mercer, 1987; Mason \& Windle, 2001). When relationships with parents are strong, adolescents are more apt to seek their advice and are more open to their influence over friendships (Brody \& Forehand, 1993). Kandel and Andrews (1987) found that parental closeness discouraged drug use directly, and indirectly through adolescents' selection of non-drug-using peers. Bogenschneider, Wu, Raffaelli, and Tsay (1998) provided additional support for this indirect effect, suggesting it is through the quality of parental relationships, rather than direct parental monitoring, that parents influence peer relationships (see also Bahr, Marcos, \& Maughan, 1995; Chassin, Pillow, Curran, Molina, \& Barrera, 1993; Mason \& Windle, 2001). By reinforcing rather than competing with parental messages, these more prosocial friendships are likely to contribute to more positive personal and behavioral outcomes. Indeed, Brown and colleagues (1986) reported that many adolescents are actually pressured by their friends against using drugs and alcohol (Patterson, Reid, \& Dishion, 1992).

Taken together, these findings imply that improvements in parent-adolescent relationships are likely to lead to reductions in substance use. As such, mentoring programs may be particularly effective in this regard. Some evidence suggests mentors shape a range of positive developmental outcomes through their influence on adolescents' parental relationships. Since mentors have the advantage of standing outside of typical parent-adolescent struggles around autonomy (Steinberg, 2001), they can provide a safe context for conversations and disclosures while transmitting adult values, advice, and perspectives (Darling, Hamilton, \& Niego, 1994; Rhodes, 2002). In a study of academic outcomes, Rhodes, Grossman, and Resch (2000) drew on the national BBBS study to examine this possibility. In addition to their direct effects on scholastic competence and school attendance, mentors' influence was partially mediated through improvements in adolescents' perceptions of their parental relationships.

Mentor relationships may also affect usage patterns through their influence on the quality of adolescents' peer relationships. Mentors' positive influence on relationship skills may facilitate adolescents' capacity to derive benefits from friendships and effectively negotiate problems that arise with peers (Rhodes, Haight, \& Briggs, 1998). Improvements in peer relations, in turn, could have several implications for substance use. Enhanced connections with prosocial peers may lead to reductions in substance use (Bogenschneider et al., 1998), whereas greater closeness with substance using peers may lead to heightened usage (Oetting \& Beauvais, 1986).

Independent of these mediating influences, mentors may directly affect substance use by conveying messages regarding its dangers (Beier, Rosenfelt, Spitalny, Zanksy, \& Bontemmpo, 2000; LoSciuto et al., 1996). Additionally, mentors' provision of emotional support and positive feedback is expected to enhance adolescents' sense of self-worth, which has been associated with reduced levels of both drug and alcohol use (Miller, 1994; Rhodes et al., 1994; Richter et al., 1992). Mentors may also serve as positive 
role models to adolescents, providing visible evidence of the benefits of reduced usage (Hamilton \& Darling, 1994; McParland \& Nettles, 1991). Through each of these processes, mentors may reinforce parents' messages regarding the dangers of drugs and alcohol and in doing so challenge the relatively pervasive pressure from peers to engage in substance use (Oetting \& Beauvais, 1986).

The processes described here are complex and in some cases involve changes in the ways that adolescents think about and approach relationships. As such, it is likely the benefits of mentoring accrue over a relatively long period of time. Grossman and Rhodes (2002), drawing on the national BBBS study, recently found that the effects of mentor relationships varied as a function of their duration. Relative to controls, youth who were in matches that lasted more than a year reported lower levels of both drug and alcohol use and higher levels of self-worth, perceived social acceptance, scholastic competence, parental relationship quality, and school value. Youth whose relationships terminated within a year derived fewer benefits and in particularly short matches youth suffered declines in self-worth and scholastic competence. These findings are consistent with a recent meta-analysis of mentoring program evaluations, which found relatively modest effects for relationships lasting less than a year (DuBois, Holloway, Cooper, \& Valentine, 2002).

This study draws from the BBBS outcome study and builds on previous findings to examine the direct and mediated effects of mentoring on the frequency of alcohol and drug use. Mentoring is expected to directly reduce the frequency of adolescents' substance use. Mentoring is also expected to affect substance use through its positive influence on parent and peer relations and self-worth. Improvements in these domains should lead to reductions in the frequency of substance use (see Figure 1). These protective processes are ex- pected to be more robust in longer-lasting relationships. As such, the conceptual models will be tested with the entire sample and then separately in relationships of varying durations. By incorporating both parent and peer relationships into the mediation model, and accounting for the effects of relationship duration, this study builds on previous work in the field.

\section{Method}

\section{Participants}

This study makes use of longitudinal data from a large sample of urban adolescents. The data were collected as part of the national evaluation of BBBS, the largest and arguably most influential evaluation of mentoring to date (Grossman \& Tierney, 1998). This study draws from 1,138 youth who participated in the BBBS programs. BBBS is open to any youth age 5 through 18 who live in an agency catchment area and agree (along with their parent or parents) to follow agency rules. In addition, most agencies give preference to youth who have no more than one parent actively engaged in their life. Applicants were randomly assigned to either the treatment or control group and administered questions at baseline and 18 months later.

Eighty-five percent ( $n=959 ; 487$ treatments and 472 controls) completed both the baseline and the follow-up interviews. The current sample consisted of 928 of these youth (31 youth who were rematched after early terminations were not included). Over $60 \%$ of this analysis sample was boys (62.9\%), and more than half were members of minority groups (60\%). Approximately $68 \%$ of the minority youth were African Americans, $17 \%$ Hispanic, and the remaining were members of a variety of other racial-ethnic groups. Participants

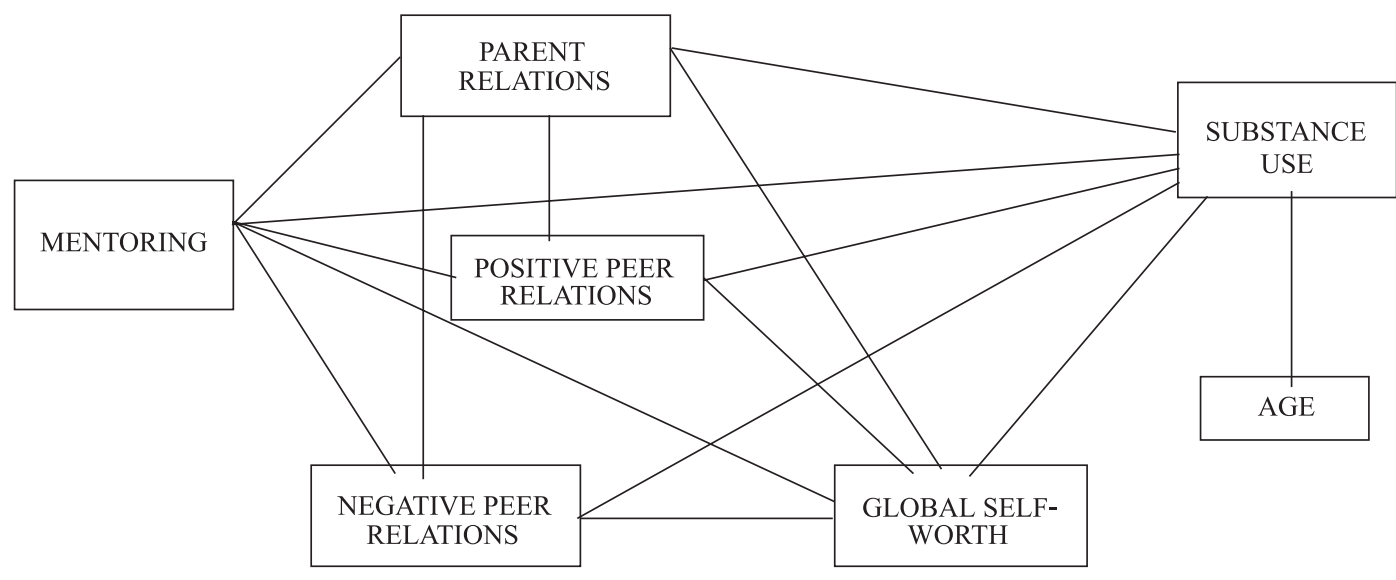

Figure 1. Graphic representation of the conceptual model. 
RHODES, REDDY, GROSSMAN

Table 1. Demographic Characteristics of Youth in Matched and Control Groups Sample Size (\%)

\begin{tabular}{|c|c|c|c|c|}
\hline Characteristics & Not Matched $^{\mathrm{a}}$ & Matched < 12 Months ${ }^{b}$ & Matched > 12 Months ${ }^{\mathrm{c}}$ & F or $\chi^{2}$ \\
\hline \multicolumn{5}{|l|}{ Youth } \\
\hline Age at assignment & 12.33 years & 12.17 years & 12.05 years & $3.13^{*}$ \\
\hline \multicolumn{5}{|l|}{ Gender } \\
\hline Male & $378(65.1)$ & $105(66.5)$ & $101(53.4)$ & \\
\hline Females & $203(34.9)$ & $53(33.5)$ & $88(46.6)$ & $9.27 * *$ \\
\hline Race & $218(38.0)$ & $69(43.7)$ & $83(44.6)$ & \\
\hline White & $242(42.2)$ & $61(38.6)$ & $71(38.2)$ & \\
\hline African American & $64(11.1)$ & $15(9.5)$ & $15(8.1)$ & \\
\hline Other & $50(8.7)$ & $13(8.2)$ & $17(9.2)$ & 10.73 \\
\hline \multicolumn{5}{|l|}{ Family } \\
\hline \multicolumn{5}{|l|}{ Parent gender } \\
\hline Male & $31(5.4)$ & $5(3.2)$ & $11(5.8)$ & \\
\hline Female & $544(94.6)$ & $153(96.8)$ & $178(94.2)$ & .47 \\
\hline \multicolumn{5}{|c|}{ Percentage of families receiving } \\
\hline \multicolumn{5}{|l|}{ Parent education } \\
\hline Some high school & $130(22.5)$ & $27(17.4)$ & $40(21.5)$ & \\
\hline High school & $240(41.5)$ & $64(41.3)$ & $73(39.2)$ & \\
\hline Some college & $167(28.8)$ & $52(33.5)$ & $58(31.2)$ & \\
\hline Bachelors & $33(5.7)$ & $6(3.9)$ & $13(7.0)$ & \\
\hline Masters and higher & $9(1.6)$ & $6(3.9)$ & $2(1.1)$ & 8.37 \\
\hline \multicolumn{5}{|l|}{ Neighborhood } \\
\hline Urban & $443(76.5)$ & $117(74.5)$ & 137 (72.9) & \\
\hline Suburban & $112(19.3)$ & 37 (23.6) & $49(26.1)$ & \\
\hline Rural & $24(4.1)$ & $3(1.9)$ & $2(1.1)$ & 8.87 \\
\hline
\end{tabular}

Note: Ten youth did not report their race. In addition, we did not have information of youth relationship with guardian, public welfare status, and parental education status for 4,7 and 8 youth respectively.

${ }^{\mathrm{a}} n=581 .{ }^{\mathrm{b}} n=158 .{ }^{\mathrm{c}} n=189$.

ranged in age from 10 to $16(M=12.24)$, most of whom $(65.4 \%)$ were between the ages of 11 and 13 . Ninety percent of youth lived with one parent $(94.7 \%$ mothers, $4.6 \%$ fathers), $5 \%$ lived with a grandparent, and the remaining participants lived in extended family or nonfamily arrangements. More than $40 \%$ of the youth lived in households receiving food stamps, public assistance, or both (see Table 1).

At the conclusion of the study, 347 (76\%) of the treatment youth had been matched, and 55.3\% of the matches had met for 12 months or more. ${ }^{1}$ The ongoing matches had been meeting for an average of 12.6 months although the closed matches met for an average of 9 months. Over $65 \%$ of the youth met with their mentor at least three times a month and approximately

\footnotetext{
${ }^{1}$ Agency staff reported three major reasons for the failure to match the 109 treatment youth during the study period. Thirty-three of the unmatched treatment youth became ineligible during the study period because the parent remarried, the youth was no longer within the eligible age range, or the youth's place of residence changed. Thirty-one were not matched because the youth no longer wanted a Big Brother or Big Sister. Twenty-one were not matched because a suitable volunteer could not be found during the study period. The 24 remaining treatment youth were not matched for a variety of reasons, most commonly because the parent or youth did not follow through with the intake process. Furthermore, 61 youth who were being served under a contractual obligation were excluded from the study.
}

$45 \%$ met one or more times per week. An average meeting lasted $3.8 \mathrm{hr}$.

\section{Design and Procedure}

From the network of more than 500 BBBS local agencies, 8 agencies were selected to participate in the outcome study. The key selection criteria for inclusion in the impact study were a large, active caseload, a waiting list, and geographic diversity. With only a few exceptions, all of the youth who enrolled in the eight selected BBBS agencies during the intake period were encouraged to participate in the research. Once a youth was informed about the study, determined to be eligible, and assented to participate (along with a parent's signed, informed consent), he or she was randomly assigned to either the treatment or control group. Only $2.7 \%$ of the youth refused to participate in the evaluation. The control group was placed on an 18-month waiting list for a poststudy match. This waiting period tended to be no longer than was typical in the participating agencies and the total number of matches made by the agencies did not decline during the study period (Tierney, Grossman, \& Resch, 1995). All participants were interviewed by telephone before they knew their experimental status. Follow-up interviews were conducted 18 months later by telephone. In addition to the 
questions administered at baseline, the follow-up surveys included items about the match, such as duration, relationship quality, and reasons for termination.

Agency staff matched particular adult volunteers with particular youth on the basis of gender (only same-sex dyads) and a variety of factors, including shared interest, reasonable geographic proximity, and same-race match preference. The majority of the volunteers were Caucasian (75.4\%) and men (59.1\%). All volunteers underwent an intensive screening process, followed by agency-based training and ongoing case management. The training covered agency policies, communication, and relationship building as well as issues that might be of particular relevance to participating youth (e.g., grieving, sexual abuse). Almost all of the mentors worked full-time $(98.1 \%)$ with the majority in managerial, professional, technical, sales, administrative support, or service areas. Sixty-one percent were single. Six had themselves been involved in the BBBS program as adolescents. Dyads typically engaged in a wide variety of leisure- and career-oriented discussions and activities with the general goal of promoting the youth's positive development.

\section{Measures}

All measures were administered to the youth orally over the telephone. The pretest administration occurred immediately after the youth were randomly assigned but before the youth were told whether they were in the treatment or control group. Posttest administration was conducted 18 months after random assignment for all youth who completed a pretest interview. For each measure, only pretest alpha reliability coefficients are reported. Posttest alphas equaled or exceeded pretest alphas in all instances. Also note that substance use was used as a broad term that included both alcohol and drug use.

Parental relationships. The Inventory of Parent and Peer Attachment (IPPA; Armsden \& Greenberg, 1987) is a 23-item scale containing questions related to a child or adolescent's relationship with his or her primary care giver (the corresponding peer questions were not administered). Responses are coded on a 4-point scale ranging from 1 (hardly ever true) to 4 (very often true). The IPPA contains three subscales: Communication (e.g., my mother can tell when I am upset about something), Trust (e.g., my father respects my feelings), and Alienation (e.g., talking over problems with my mother makes me feel ashamed or foolish). Higher scores on the scale reflect more positive parent-youth relations. At pretest, Cronbach's alpha reliability coefficients of the subscales and the total scale were $.72, .71, .73$, and .66 , respectively.
Features of Children's Friendship Scale (Berndt \& Perry, 1986). This 25 -item scale consists of five subscales, each representing a different support or problem domain. The five subscales with example questions were (a) Intimacy (e.g., "Do you talk to your friends about something that bothers you?"), (b) Self-Esteem Enhancement (e.g., "Do your friends give you the confidence to do something you thought you couldn't do?"), (c) Prosocial Support (e.g., "Would your friends agree to do a favor for you if you asked?"), (d) Conflict (e.g., "Do you get into arguments with your friends?"), and (e) Inequality (e.g., "Do your friends try to boss you around?"). Responses were coded on a 4-point scale, ranging from 1 (hardly ever) to 4 (pretty often). At baseline internal reliability alpha coefficients of the subscales ranged from .61 to .69. For reasons of parsimony and to examine if we could identify separate positive and negative perceptions of peer relations, these subscales were subjected to factor analyses. Factor analyses of the peer scales at pretest and posttest revealed two robust factors. Intimacy, Self-Esteem Enhancement, and Prosocial subscales loaded on a "positive" peer relation dimension although Conflict and Inequality loaded on a "negative" peer relation dimension. ${ }^{2}$ Low correlation existed between the factors. For each youth, a positive and negative peer relations score was obtained from summing the items of the respective subscales. These factors aided in examining the differential effects of mentoring on peer relations and their effect on substance use. High scores on the positive scale reflected more intimate and prosocial peer relations. High scores on the negative subscale, on the other hand, reflected peer relations that were viewed as conflictual.

Self-Worth. This six-item subscale of the Self-Perception Profile for Children (Harter, 1985) contains statements describing the global self-worth of two groups (e.g., "some kids are pretty pleased with themselves, other kids are often unhappy with themselves"). Respondents were asked to determine whether they were more like the first or second group and whether the statement was "really true" or "sort of

\footnotetext{
${ }^{2}$ Principal Axis Factor analysis with oblimin rotation with Kaiser normalization was utilized. Percentage of variance explained at Time 1 and Time 2 was $56.49 \%$ and $61.92 \%$, respectively. Factor loadings at both time points were above .60 for all variables. Correlation between the factors was $r=.27$ (Time 1) and $r=.20$ (Time 2). Items were recoded such that higher values on the scales imply more positive peer relations and lower levels of conflict and inequality. It should be noted that, the peer measures may not be reliable across wide age range present in the study sample. To examine this possibility, we calculated reliabilities of the positive and negative peer measures for the 9-12 year and 13-16 year age groups at Time 1 and Time 2. For the positive peer measure, alphas for the two age groups were .81 and .84 at Time 1 and .84 and .85 at Time 2 respectively. For the negative peer measure, the alphas were .79 and .81 at Time 1 and .82 and .79 at Time 2 for the two age groups, respectively.
} 
true" for them $(\alpha=.70)$. Higher scores on this subscale implied that the youth were content and happy about themselves as a person.

Social Acceptance. This six-item subscale of the Self-Perception Profile for Children (Harter, 1985) contains statements describing ease of making friends and acceptance of peers, dividing children into two groups (e.g., "some kids wish that more people their age liked them, other kids feel that most people their age do like them"). Respondents were asked to determine if they were more like the first or second group and whether the statement was "really true" or "sort of true" for them $(\alpha=.69)$. High scores reflected youth who had no problems making friends or being accepted by their social group.

Alcohol and drug use. Single items were used to assess the frequency of alcohol and drug use. Using an open-ended scale, the youth were asked "How many times did you drink alcohol since the last month?" The youth were asked not to take into consideration sips of alcohol that they may have had as part of a religious ceremony or at a family gathering such as a wedding. A parallel item was used to record frequency of drug use. The youth were asked "How many times did you use drugs in the last month?" A further qualification was made that the drugs were other than medicines they may have taken for health reasons. Marijuana and cocaine were given as examples of possible drugs.

Match status. Match status was coded dichotomously with 0 (not matched with a mentor) and 1 (matched; mentoring). To avoid biases in the measurement of mentoring effects, both matched and unmatched treatment participants were included in the analyses.

\section{Results}

\section{Descriptive Statistics}

With the exception of age and gender, youth in the treatment group did not differ from the control group on any of the variables of interest at baseline (see Tables 1 and 2). Youth in longerterm matches tended to be slightly younger $(M=12.05)$ than those not matched $(M=12.32)$ and were more likely to be girls, $\chi^{2}(2, N=928)=9.27, p=.01$. Comparisons among youth in matches of various lengths (i.e., 1 to 6 months, 7 to 12 months, and 13 to 19 months) showed that there were no overall differences in the frequency with which the matches met, $\chi^{2}(8, N=329)=12.28, p>.10$.

Although the observed means and variances of adolescent alcohol and drug use increased over time, only $16 \%$ and $2.2 \%$ of the youth reported alcohol and drug use at baseline, respectively. By posttest, 29\% and $9 \%$ of the youth reported alcohol and drug use, respectively. The substance use data therefore displayed relatively high degree of skew and kurtosis and were non-normally distributed. This significant skew in the alcohol variable led us to use the Satorra-Bentler method of estimation, an estimation that is more robust to nonnormality than maximum likelihood (Satorra \& Bentler, 1988). The alcohol use variable well-suited this method as it was a non-normal continuous variable (range of the variable spanned 0-20 with more than 13 categories defined at baseline and posttest). Because drug use, in particular, displayed a high degree of kurtosis, it was decided that separate analyses for alcohol and drug use were to be conducted. Moreover, the drug use variable was transformed using the logarithmic transformation and all analyses were conducted on this transformed variable. The decision to conduct separate analysis also fit into the developmental patterns of use among adolescents. Many researchers, based on longitudinal data sets, have argued that alcohol use serves as a "gateway" to the use of other illicit substances (e.g., Kandel, 1980; Kandel \& Yamaguchi, 1993). Trends based on cross-sectional data have also found that in general, alcohol use is more likely to have initiated at an earlier age than drugs (Johnston et al., 2001, O’Malley, Johnston, \& Bachman, 1998).

\section{Alcohol Use}

Model specification and evaluation strategy. The conceptual model was tested using structural equation modeling procedures. Although distribution-free statistics are recommended estimators for such non-normal data, Monte Carlo studies have found them to behave reliably only under large sample sizes (Curran, West, \& Finch, 1996; Hu, Bentler, $\&$ Kano, 1992). One strategy for conducting analyses with non-normal data sets is to use maximum likelihood estimators with corrected statistics. This reduces biases in the calculation of the standard errors and the chi-square values (see also Chou \& Bentler, 1995; Kline, 1998). This estimation procedure was therefore used for the analyses of alcohol use, with the caveat that the lower chi-square values may indeed reflect decreased power to detect model misspecifications.

Asymptotic covariance matrices were estimated using LISREL 8.30 (Jöreskog \& Sörbom, 2000). Parameter estimates were based on maximum-likelihood procedures but standard errors and chi-square values were estimated under non-normality. Specifically, we employed the scaled chi-square statistic provided by Satorra and Bentler (see Jöreskog, Sörbom, du Toit, \& du Toit, 1999). Model fit was as- 
Table 2. Baseline and Posttest Differences Between Youth in Matched or Control Groups

\begin{tabular}{|c|c|c|c|c|c|c|}
\hline \multirow[b]{2}{*}{ Variable } & \multicolumn{3}{|c|}{ Baseline } & \multicolumn{3}{|c|}{ Posttest } \\
\hline & $\begin{array}{l}\text { Not Matched }^{\mathrm{a}} \\
\% \text { or M (SD) }\end{array}$ & $\begin{array}{c}\text { Matched }<12 \text { Months }{ }^{\mathrm{b}} \\
\% \text { or M(SD) }\end{array}$ & $\begin{array}{c}\text { Matched > } 12 \text { Months }{ }^{\mathrm{c}} \\
\% \text { or M (SD) }\end{array}$ & $\begin{array}{l}\text { Not Matched }{ }^{\mathrm{a}} \\
\text { \% or M(SD) }\end{array}$ & $\begin{array}{c}\text { Matched }<12 \text { Months }{ }^{\mathrm{b}} \\
\% \text { or M(SD) }\end{array}$ & $\begin{array}{c}\text { Matched > } 12 \text { Months } \\
\% \text { or M (SD) }\end{array}$ \\
\hline Frequency of alcohol use & 16.50 & 17.10 & 13.20 & 30.30 & 31.00 & 21.20 \\
\hline Frequency of drug use & 1.90 & 3.80 & 1.60 & 10.7 & 10.10 & 3.70 \\
\hline Parent relations & $71.66(10.92)$ & $70.47(12.03)$ & $72.36(10.96)$ & $70.92(13.04)$ & $70.96(12.68)$ & 73.14 (12.39) \\
\hline Positive peer relations & $35.43(7.40)$ & $36.23(6.73)$ & $36.36(7.23)$ & $36.67(7.21)$ & $36.92(7.34)$ & $37.62(7.03)$ \\
\hline Negative peer relations & $22.36(5.67)$ & $23.11(5.76)$ & $22.79(6.14)$ & $23.50(5.52)$ & $24.11(5.82)$ & $24.35(5.28)$ \\
\hline Global self-worth & $17.97(4.28)$ & $17.70(4.44)$ & $18.27(4.23)$ & $18.72(4.30)$ & $18.33(4.44)$ & $19.39(3.95)$ \\
\hline
\end{tabular}

Note: Numbers for alcohol and drug use reflect the percentage of youth who reported use and baseline and posttest respectively. None of the differences were significant at baseline. $\mathrm{a}_{n}=581 . \mathrm{b}_{n}=158 . \mathrm{c}_{n}=189$. 
sessed using multiple goodness-of-fit indexes (GFI) provided by the program. These indexes reflect the degree to which the specified model is reproduced in the observed covariance matrix. In this study, the following goodness-of-fits were used to evaluate model fit: (a) Satorra-Bentler (SB) scaled $\chi^{2}$ value, (b) root mean square error of approximation (RMSEA), (c) GFI and Adjusted GFI (AGFI), (d) standard root mean square residual (RMR), and (e) the comparative fit index (CFI). The incremental fit index CFI was added to the list of GOFs as it assesses improvements in the observed model over a null model in which variables are uncorrelated (Bollen, 1989; Kline, 1998; Steiger, 1990) and has a smaller downward bias under severely non-normal conditions (West, Finch, \& Curran, 1995). In all models temporally prior variables were specified to influence respective posttest variables.

As depicted in the model (see Figure 1), mentoring was expected to reduce alcohol use both directly and indirectly, through improvements in parental relationships, higher levels of self-worth, and more positive peer relations. Improved parental relationships were hypothesized to discourage substance use both directly and indirectly through their positive influence on self-worth and peer relationships. Improved peer relationships were expected to lead to reductions in substance use directly and indirectly through self-worth. Age was controlled for in the models. Because a model that included gender revealed no significant differences, and gender was not a significant predictor of alcohol use, it was excluded from the ensuing analyses. Mediation of mentoring through improved parental and peer relations were tested using nested models. Comparing the relative fit of these nested models tests whether improved parental and peer relations are partial mediators of the effects of mentoring on the frequency of substance use. In addition, wherever applicable, we also provided both direct and indirect effects of mentoring on alcohol use, using Sobel's method of decomposition of effects provided in LISREL through the EF option in the output statement.

Unstandardized and standardized (in parentheses) path coefficients are shown in Figure 2. Although all paths were estimated, only the significant paths are shown for the sake of clarity. The model represents the pathways by which being matched with a mentor influenced substance use 18 months later. Although the SB chi-square statistic for the hypothesized model was significant, SB $\chi^{2}(25, N=928)=39.00, p<.05$, the other GOFs indicated a well-fitting model (RMSEA = $.03, \mathrm{GFI}=.99, \mathrm{AGFI}=.98, \mathrm{Std} \mathrm{RMR}=.02, \mathrm{CFI}=.99$ ). Contrary to our expectations however, being matched with a mentor was not significantly related to either frequency of substance use, self-worth, or peer relations (as indexed by the nonsignificant path coefficients). Mentoring only showed a marginal influence on posttest parental relationships, $1.32(.05), p=.08$. Examining the decomposition of effects also revealed nonsignificant total direct effects (-.30), $t=-1.65, p>$ .05 , and indirect effects (-.04), $t=-1.09, p>.05$, of mentoring on alcohol use.

Because longer term relationships tend to be relatively more influential (Grossman \& Rhodes, 2002), the wide variation in length among relationships

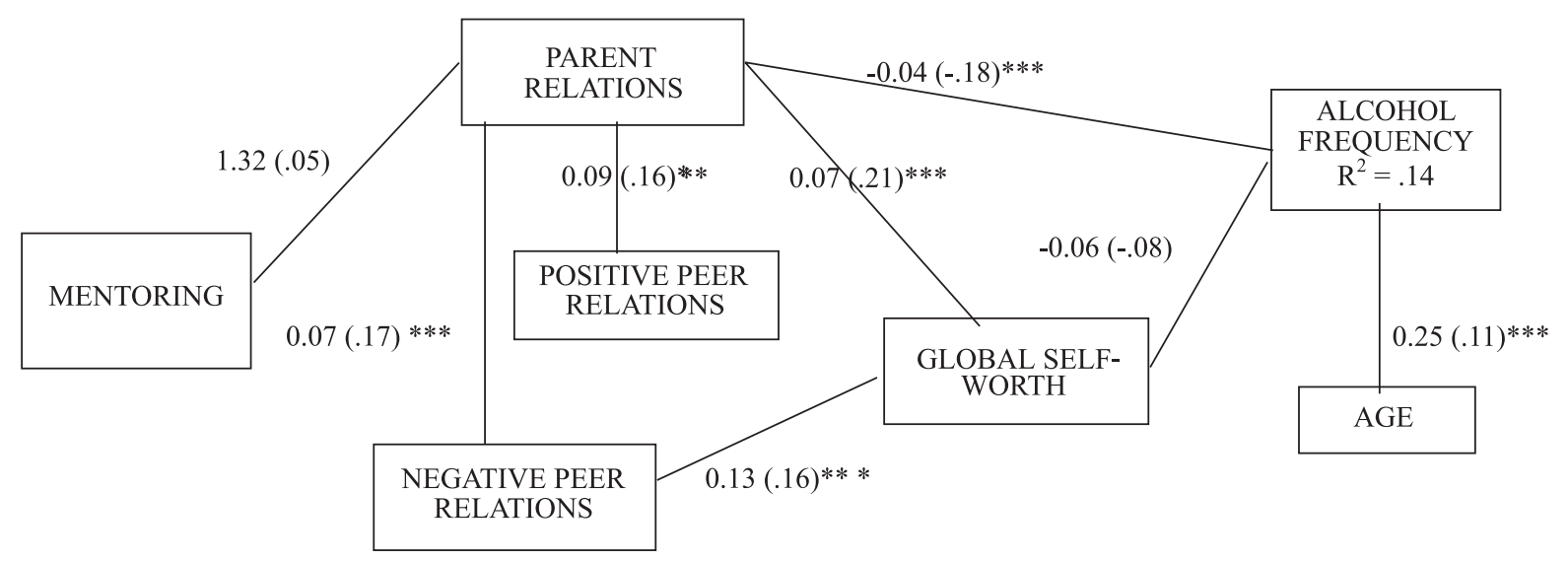

Figure 2. Unstandardized (standardized) coefficients for the hypothesized model. For the sake of clarity, only statistically significant paths are presented. All paths among independent variable (mentoring) and the endogenous variables were estimated. Note that the hypothesized model is a recursive model. Only unidirectional paths between positive peer and negative peer relations and frequency of alcohol and drug use were estimated. Dashed lines represent a significant relationship at the $p<.10$ level. $* p<.05, * * p<.01, * * * p<.001$. Goodness-of-fit Indices: SB $\chi^{2}(25, N=928)=39.00, p<.05$, RMSEA $=.03$, GFI $=.99$, AGFI $=.98$, Std RMR $=.02$, CFI $=.99$. 


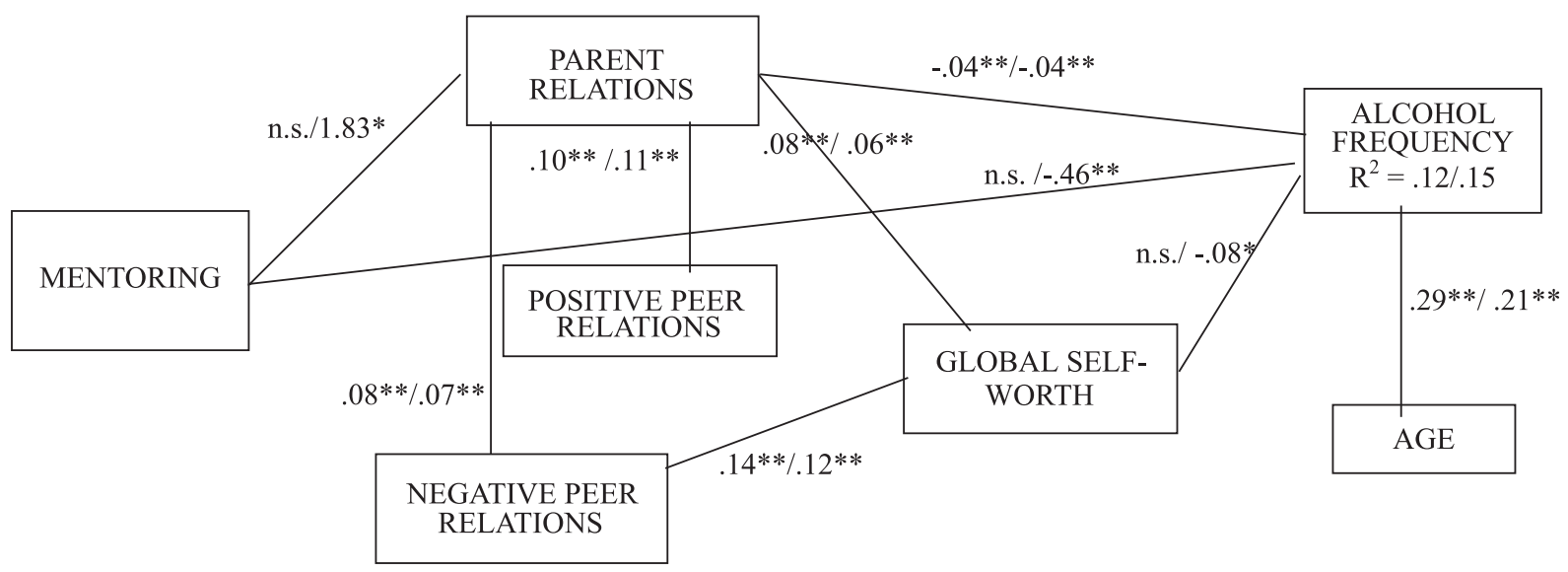

Figure 3. Unstandardized coefficients for the hypothesized model for the two subgroups: youth matched for less than 12 months (Group A) and those matched for 12 months or more (Group B). For the sake of clarity only statistically significant paths are presented. Coefficients for Group A are presented first followed by those for Group B. $* p<.05, * * p<.01, * * * p<.001$. Goodness-of-Fit Indices: Group A: SB $\chi^{2}(25, N=739)=33.95, p=.11$, RMSEA $=.02$, GFI $=.99$, AGFI $=.98$, Std RMR $=.02$, CFI $=.99$. Group B: SB $\chi^{2}(25, N=$ 770 $)=20.86, p=.70$, RMSEA $<.01$, GFI $=.99$, AGFI $=.97$, Std RMR $=.03$, CFI $=.98$.

might have masked the influence of mentoring. To examine the possibility of the moderating effects of duration, we utilized multigroup testing. We reestimated the models with two subgroups, those who were matched with a mentor for less than 12 months (group A, $n=158$ ) and those who were matched for 12 months or more (group B, $n=189$ ). Each of these groups was contrasted against the group of youth who were not matched with a mentor $(n=581)$.

The hypothesized model fit the data well for both group A $\left(\mathrm{SB} \chi^{2}(25, N=739)=33.95, p=.11\right.$, RMSEA $=.02$, GFI $=.99$, AGFI $=.98$, Std RMR $=$ $.02, \mathrm{CFI}=.99)$ and group $\mathrm{B}\left(\mathrm{SB} \chi^{2}(25, N=770)=\right.$ 20.86, $p=.70$, RMSEA $<.01$, GFI $=.99$, AGFI $=$ .97$, Std RMR $=.03, \mathrm{CFI}=.98)$. The model explained $12.3 \%$ and $15.4 \%$ of the variance in alcohol use in groups A and B, respectively. The path coefficients for the models are shown in Figure 3 and represent the influence of match duration on alcohol use at posttest for the two groups of adolescents compared against the controls. As indicated by the nonsignificant path coefficients, there was no difference between being in a mentoring relationship for less than 12 months and not being matched at all. Mentoring did not impact substance use or any of the other hypothesized variables at posttest. Decomposition of effects revealed nonsignificant total direct $(-.03), t=-.18, p>.05$, and indirect $(-.00), t=-.05$, $p>.05$, effects were not significant. For youth who were with their mentors for 12 months or longer, however, being matched had significant impacts on the frequency of alcohol use $(-.46, p<.01)$ and pa- rental relationships $(1.83, p<.05) .^{3}$ Improved parental relationships, in turn, were significantly associated with all endogenous variables in the expected direction, including decreased alcohol use $(-.04, p<.01)$, increased in self-worth $(.06,<.01)$, positive peer relations $(.11, p<.01)$, and reduced conflict and feelings of inadequacy with peers $(.07, p<.01)$. Decomposition of effects revealed a strong, significant direct effect of mentoring on alcohol use (-.54), $t=-3.15, p<$ .01 . The total indirect effect of mentoring through all the other variables in the model was not significant $(-.08), t=-1.55, p>.05$.

Because a primary aim of this study was to explore pathways of influence, we directed our attention to the subgroup of adolescents who were in longer matches (group B). To further test the mediating role of parental relationships in this subgroup, an alternative, nested model was tested in which the quality of

\footnotetext{
${ }^{3}$ Although these paths seem to indicate differences between the groups varying on length of match, multigroup testing is needed to verify statistical significance. The hypothesized model was constrained to be equal across both groups and the paths of substantive interest were freed. An examination of the difference in chi-square will permit a test of the comparative significance of the paths between the groups. Nested models were tested sequentially freeing paths between mentoring and alcohol use, and parent relations. Nonsignificant chi-square difference tests revealed that the paths are not significantly different in magnitude across the groups. However, youth in mentoring relationships lasting at least a year or longer evidenced significant improvements in parent relationships and alcohol use compared to their counterparts in the control group. Given that a primary goal of mentoring programs is to enhance youth development, exploring and understanding pathways of mentoring influence on substance use is essential. We therefore focused on the path model for youth matched greater than 12 months.
} 


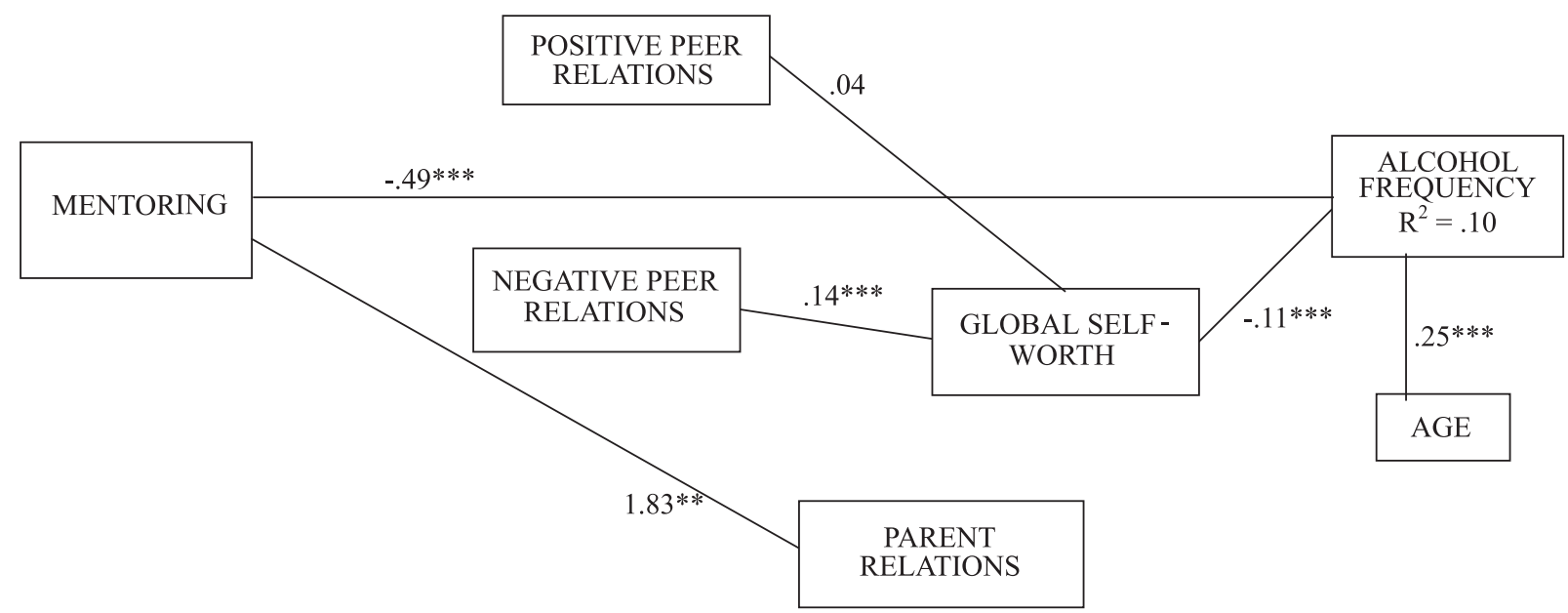

Figure 4. Unstandardized coefficients for the alternative model for youth matched for 12 months or more. Dashed lines represent a significant relationship at the $p<.10$ level. $* p<.05$, ** $p<.01$, ***p $<.001$. Goodness-of-Fit Indices: $\mathrm{SB} \chi^{2}(29, N=770)=137.39, p<.001$, RMSEA $=.07$, GFI $=.97$, AGFI $=.92$, Std RMR $=.05$, CFI $=.89$.

parent relations was treated solely as an outcome variable rather than a mediator and compared against the original hypothesized model. Chi-square tests of difference between the original and alternative models were then examined. A large, significant chi-square difference was obtained when the alternative model was compared to the original hypothesized model, $\chi^{2}$ diff $(4)=103.99, p<.001$, suggesting that parental relationships partially mediated the relationship between mentoring and substance use. Figure 4 shows the unstandardized path coefficients of the alternative model. To further explore the specific hypothesized role of parent relations on adolescent alcohol use, the paths between parent relations and self-worth were specified as null and the models were reestimated (see Table 3). In each instance, the alternative nested model yielded a poorer fit, indicating that improved parental relationships led to reductions in adolescent alcohol use both directly and indirectly through increases in adolescents' self-worth.

\section{Drug Use}

Model specification and evaluation strategy. Given the degree of kurtosis in the drug use variable, $\log$ transformation of the variable was used in all analyses. As expected, the log transformations affected approximately $10 \%$ of the data. Moreover, rather than employing structural equation modeling, the effects of mentoring on drug use at posttest were examined using ordinary least squares regression (OLS). These data analytic strategies tend to be more resistant to departures from normality, especially with larger sample sizes (Tabachnick \& Fidel, 1998). Our goal was to translate, as reliably as possible, the conceptual model using OLS. Rather than simultaneously measuring the effects of the variables on each other, OLS models can only be tested in discreet steps. Direct and mediated effects of mentoring on drug use were thus estimated using a series of multiple regression equations. Standardized coefficients are presented in each model so that the relative strength of each path can be appraised.

Table 3. Comparison of the Nested Models for Youth Matched for 12 Months or More.

\begin{tabular}{|c|c|c|c|c|c|c|c|}
\hline Model & $\chi^{2}$ & df & AGFI & RMSEA & $\Delta \mathbf{d f}$ & $\Delta \chi^{2}$ & $\mathbf{p}(\mathbf{d})$ \\
\hline Hypothesized model & 65.27 & 31 & .96 & .04 & & & \\
\hline Alternative model & 180.80 & 36 & .91 & .07 & 6 & 115.53 & .000 \\
\hline \multicolumn{8}{|l|}{$\begin{array}{l}\text { Testing individual pathways of } \\
\text { parent relations influence }\end{array}$} \\
\hline Parent $\rightarrow$ alcohol use & 84.14 & 32 & .95 & .05 & 1 & 18.87 & .000 \\
\hline Parent $\rightarrow$ global self-worth & 98.07 & 32 & .95 & .05 & 1 & 32.80 & .000 \\
\hline Parent $\rightarrow$ Positive peer relations & 98.71 & 32 & .95 & .05 & 1 & 33.44 & .000 \\
\hline
\end{tabular}

Note: AGFI $=$ adjusted goodness-of-fit index; RMSEA = root square mean error of approximation .

a Each of the following paths of substantive interest was specified as zero and the model reestimated. This allowed the test of the influence of the quality of parental relationships on the frequency of alcohol use directly and indirectly through global self-worth and positive peer relations. 
A full model was first estimated in which drug use was regressed on all of the variables in the model (see Figure 1). Models with gender revealed no significant differences and gender was not a significant predictor of drug use, hence it was excluded from all ensuing analyses. In Step 1, demographic (age) and pretest (baseline) variables were entered. Step 2 consisted of self-worth and parent and peer relations reported at posttest. The last step incorporated a dummy variable representing membership in the control versus matched conditions. This permitted an examination of the direct effects of mentoring on drug use, controlling for all other variables in the model. Mediated effects were tested using procedures outlined by Baron and Kenny (1986).

\section{Direct Effects of Mentoring}

The full model was estimated on the whole sample and accounted for $7 \%$ of the variance in drug use. Controlling for pretest (baseline) use, positive parent relations at posttest negatively predicted drug use at posttest $(\beta=-.11, p<.01)$. Being in a mentoring relationship, however, did not significantly predict drug use. ${ }^{4}$ Furthermore mentoring did not significantly predict any of the hypothesized mediators. Tests of mediation were therefore not possible. In keeping with the alcohol modeling, we thus tested the possibility that the duration of the match was masking the effects of mentoring. In OLS such comparisons are typically tested using dummy variables-in this case representing youth not matched, youth matched for less than 12 months, and youth matched for 12 months and longer. Because our primary goal was to study direct and mediated effects of mentoring and to maintain an analysis strategy symmetrical to the alcohol use strategy, the models for drug use were tested separately for youth in longer mentoring relationship (12 months or longer) and for youth in shorter relationship (less than 12 months). This also aided in testing a more parsimonious model.

For each subgroup, treatment youth were contrasted against controls using a dummy variable for mentoring status. The full model was tested followed by tests of the mediating pathways. In these latter

\footnotetext{
${ }^{4}$ Logistic regression of youth report of any drug use at posttest was also examined. The dependent dichotomous variable contrasted youth who report using drugs to those who report never having used drugs. Blocks similar to the full model were employed. Length of relationship predicted the dependent variable above and beyond the parent, peer, and self-worth variables (log likelihood ratio: $\left.\chi^{2}(1, N=928)=6.85, p<.01\right)$. The final model correctly classified $90.4 \%$ of the cases and explained $22 \%$ of the variance (Nagelkerke $R^{2}$ ). Unit change in age and positive peer relations increased the odds of reporting drug use at posttest. A positive parent-youth relationship, higher self-worth, and being in a longer relationship decreased the same odds, albeit by a small degree (ratios less than 1.0).
}

tests, the conceptualized model was partitioned into different submodels. The first set of submodels regressed mentoring status onto each of the hypothesized mediating variables. Three multiple regression equations were estimated for each of the presumed mediators (see Table 4). As described by Baron and Kenny (1986), mediation is evidenced if (a) mentor status is a significant predictor of the mediator (i.e., the dependent variable in the first equation), (b) mentor status is a significant predictor of drug use in Equation 2, (c) the mediator significantly predicts drug use in the third equation, and (d) with the introduction of the mediator, the previously significant relationships between mentoring status and drug use reduces to zero (perfect mediation) or is significantly attenuated (partial mediation).

The role of self-worth as a mediator of parent and peer relations on drug use was evaluated next, followed by tests of the role of peer relationships in mediating the effects of parental relationships on both drug use and self-worth. Each of these mediating hypotheses required a set of three equations to be estimated, which parallel those described previously. The analyses were conducted separately with youth in longer and shorter matches. In each case, youth were contrasted against their counterparts in the control condition. ${ }^{5}$

\section{Direct and Mediating Effects of Mentoring for Youth in Longer Matches}

The full model was estimated and accounted for $7 \%$ of the variance in drug use. Mentoring significantly predicted decreased drug use $(\beta=-.07, p<$ $.05)$ at posttest, controlling all other variables in the model, $F(1, N=758)=4.06, p<.05$. Moreover, improved parental relationships were associated with lower reported levels of use at posttest, controlling for baseline levels $(\beta=.13, p<.01)$. Tests of mediation followed. For each of the four tests of mediating effects, a series of three equations paralleling those described previously were estimated (see Table 4). As indicated in Equations 1 through 3, mentoring had no significant influence on positive peer relationships $(\beta$ $=.04, p=.29)$, negative peer relationships $(\beta=.05, p$ $=.16)$, or self-worth $(\beta=.06, p=.09)$. Hence, no test

${ }^{5}$ For models testing Equations 4 through 12, this necessitated incorporating the interaction of the mentor status term with the other independent variables in the model to indicate moderation by mentoring status. The independent variables were therefore centered to avoid problems of multicollinearity (Aiken \& West, 1991). In each set of regressions, these interaction terms were entered following the entry of the control and centered independent variables. Mediation was then tested and inferred by the procedures outlined by Baron and Kenny (1986) and noted in the text. Moderation was not supported in any of the models (i.e., mentoring status had little influence in the pattern of relationships among variables in Equations 4 through 12). We therefore report the results of the nonmoderating model. 
Table 4. Tests of Mediation for the Path Model of Mentoring on Log Drug Use

\begin{tabular}{|c|c|c|c|c|c|c|}
\hline \multirow[b]{2}{*}{ Equation } & \multirow{2}{*}{$\begin{array}{c}\text { Dependent } \\
\text { Variables (Y) }\end{array}$} & \multirow{2}{*}{$\begin{array}{l}\text { Independent } \\
\text { Variables (X) }\end{array}$} & \multicolumn{2}{|c|}{$\begin{array}{l}\text { Shorter Matches } \\
\text { (<12 Months) }\end{array}$} & \multicolumn{2}{|c|}{$\begin{array}{l}\text { Longer Matches } \\
\text { (= 12 Months) }\end{array}$} \\
\hline & & & Beta & F Change & Beta & F Change \\
\hline \multicolumn{7}{|c|}{ Mentor $\rightarrow$ Parent, Peer $\rightarrow$ Use } \\
\hline 1a & Parent relations & Mentor & .02 & .470 & $.06 *$ & $3.74 * *$ \\
\hline $\mathrm{b}$ & Positive peer & Mentor & -.004 & .012 & .04 & 1.14 \\
\hline c & Negative peer & Mentor & .03 & .669 & .05 & 1.95 \\
\hline $\mathrm{d}$ & Self-worth & Mentor & -.03 & .660 & .06 & 2.83 \\
\hline 2 & Log drug use & Mentor & - & - & $-.07 *$ & $4.18^{*}$ \\
\hline \multirow[t]{2}{*}{3} & Log drug use & Mentor & - & - & -.06 & \\
\hline & & Parent relations & - & - & $-.13 * * *$ & $7.57 * * *$ \\
\hline \multicolumn{7}{|c|}{ Parent, Peer $\rightarrow$ Self-worth $\rightarrow$ Use } \\
\hline \multirow[t]{3}{*}{4} & Self-worth & Parent relations & - & - & $.18 * * *$ & \\
\hline & & Positive peer & - & - & .04 & \\
\hline & & Negative peer & - & - & .15 & $13.66 * * *$ \\
\hline \multirow[t]{3}{*}{5} & Log drug use & Parent relations & - & - & $.13 * * *$ & \\
\hline & & Positive peer & - & - & -.002 & \\
\hline & & Negative peer & - & - & .05 & $4.16^{* *}$ \\
\hline \multirow[t]{4}{*}{6} & Log drug use & Parent relations & - & - & $-.13 * *$ & \\
\hline & & Positive peer & - & - & .00 & \\
\hline & & Negative peer & - & - & .06 & \\
\hline & & Self-worth & - & - & -.06 & $3.80 * *$ \\
\hline \multicolumn{7}{|c|}{ Parent, Peer $\rightarrow$ Use } \\
\hline $7 \mathrm{a}$ & Positive peer & Parent relations & - & - & $.20 * * *$ & $14.14 * * *$ \\
\hline $8 \mathrm{a}$ & Log drug use & Parent relations & - & - & $-.14 * * *$ & $7.76 * * *$ \\
\hline \multirow[t]{3}{*}{$9 \mathrm{a}$} & Log drug use & Parent relations & - & - & $-.13 * * *$ & \\
\hline & & Positive peer & - & - & .01 & $5.04 * *$ \\
\hline & & & - & - & & \\
\hline $7 \mathrm{~b}$ & Negative peer & Parent relations & - & - & $.13 * * *$ & $6.80^{* * *}$ \\
\hline \multirow[t]{2}{*}{$9 b$} & Log drug use & Parent relations & - & - & $-.14 * * *$ & \\
\hline & & Negative peer & - & - & .05 & $5.54 * * *$ \\
\hline \multicolumn{7}{|c|}{ Parent $\rightarrow$ Peer $\rightarrow$ Self-worth } \\
\hline $10 \mathrm{a}$ & Positive peer & Parent relations & - & - & $.20 * * *$ & $14.14 * * *$ \\
\hline $11 \mathrm{a}$ & Self-worth & Parent relations & - & - & $.20 * * *$ & $15.48 * * *$ \\
\hline \multirow[t]{2}{*}{$12 \mathrm{a}$} & Self-worth & Parent relations & - & - & $.19 * * *$ & \\
\hline & & Positive peer & - & - & .06 & $11.35 * * *$ \\
\hline $10 \mathrm{~b}$ & Negative peer & Parent relations & - & - & $.13^{* * *}$ & $6.80 * * *$ \\
\hline \multirow[t]{2}{*}{$12 \mathrm{~b}$} & Self-worth & Parent relations & - & - & $.18 * * *$ & \\
\hline & & Negative peer & - & - & $.16 * * *$ & $17.90 * * *$ \\
\hline
\end{tabular}

Note: Standardized coefficients are reported. Mentoring status was defined with a dummy variable such as 0 (controls) or 1 (matched 12 months or more/matched less than 12 months). Longer matches, $N=770$; shorter matches, $N=739$. Baseline levels were controlled in all equations. In addition, age was controlled in equations with log. Each set of equations (i.e., 1-3, 4-6; 7-9; 10-12) represent tests of mediation as outlined by Baron and Kenny (1986). Bold coefficients represent pathways that were mediated.

$* p<.05 . * * p<.01 . * * * p<.001$.

of the mediating role of these variables was possible. By contrast, mentoring significantly predicted improved parental relationships. Compared to their counterparts in the control condition, youth in longer-lasting mentoring relations evidenced better parental relationships at posttest $(\beta=.06, p=.05)$. The mediating hypothesis of the role of parental relationships was further explored.

Consistent with the alcohol model, mentoring was significantly associated with decreased drug use at posttest $(\beta=-.07, p<.05$; see Table 4$)$. In addition, improvements in parental relationships were associated with decreases in drug use at posttest $(\beta=-.13, p<$ .01). Furthermore, introducing parental relationships as a mediator negated the impact of mentoring on drug use. The previously significant relationship between mentoring and drug use reduced and was no longer statistically significant $(\beta=-.06, p=.07)$. This suggests that the effect of mentoring on drug use is fully mediated by parental relationships for youth in longer lasting matches.

The potential role of self-worth as a mediator of parent and peer relationships on drug use was then explored using Equations 4 through 6. Positive peer relationships were not significantly related to self-worth $(\beta=.04, p=.31)$ and hence no test of mediation was possible. By contrast, parent relations $(\beta$ $=.17, p<.01)$ and negative peer relationships $(\beta=$ 
$.15, p<.01)$ were significantly related to self-worth. Positive parental relationships and the absence of negative peer relationships were associated with higher levels of self-worth. However as seen in Table 4 , self-worth did not mediate the relationship between parent and peer relationships and drug use. Negative peer relationships were not significantly related to drug use ( $\beta=.06, p=.16)$. In addition, whereas parental relationships led to decreased drug use $(\beta=$ $.13, p=.01)$ at posttest, self-worth did not significantly influence drug use at posttest $(\beta=-.06, p=$ .14). Similar conclusions were reached with respect to the role of positive and negative peer relationships as mediators between parental relationships and drug use (Equations 7 through 9). Although parental relationships were strongly and significantly associated with positive $(\beta=.20, p<.01)$ and negative $(\beta=.13$, $p<.01)$ peer relationships, these variables did not significantly predict drug use at Time 2 (positive peer relationships: $\beta=.01, p=.75$; negative peer relationships: $\beta=.05, p=.20$ ).

The last set of mediating hypotheses included the role of peer relationships as mediators of parental relationships on self-worth (Equations 10 through 12). Although positive peer relationships did not mediate the relationship between parental relationships and self-worth, negative peer relationships attenuated the relationship between parental relationships and self-worth. In particular, the beta coefficient reduced from .20,p<.01 to .18, $p<.01$ (see Table 4). To test if this reduction was statistically significant, the Sobel procedure (see Baron \& Kenny, 1986) was employed. This yielded a $t$ ratio of 2.82 , suggesting that the absence of negative relations with peers partially medi- ates the influence of parental relationships on self-worth.

Figure 5 provides a graphic representation of the statistically significant betas shown in Table 4 for adolescents in longer matches. It should be noted that direct paths between mentoring and the other endogenous variables in the model represent comparisons between the matched and the control groups.

A parallel set of analyses was conducted for youth in shorter matches. In this case, mentoring did not influence drug use at posttest, $F(1, N=727)=.466, p=$ $.49 ; R^{2}$ adjusted $=.06$, and there were also no significant relationships between mentoring and any of the proposed mediating variables (see Table 4). Hence no further mediating hypotheses were tested.

\section{Discussion}

Although our conceptual model was not confirmed with data from the entire sample or the shorter-term subsample, it fit reasonably well when applied to data from the longer-term subsample. Longer-term mentoring directly affected the frequency of substance use and led to significant changes in adolescents' perceptions of parental relationships. Improvements in perceptions of parental relationships were directly associated with reductions in substance use, improvements in peer relationships, and higher levels of self-worth. Moreover, improvements in self-worth negatively predicted the frequency of adolescents' alcohol use.

Consistent with previous work, mentors' influence appears to be partially mediated through improved

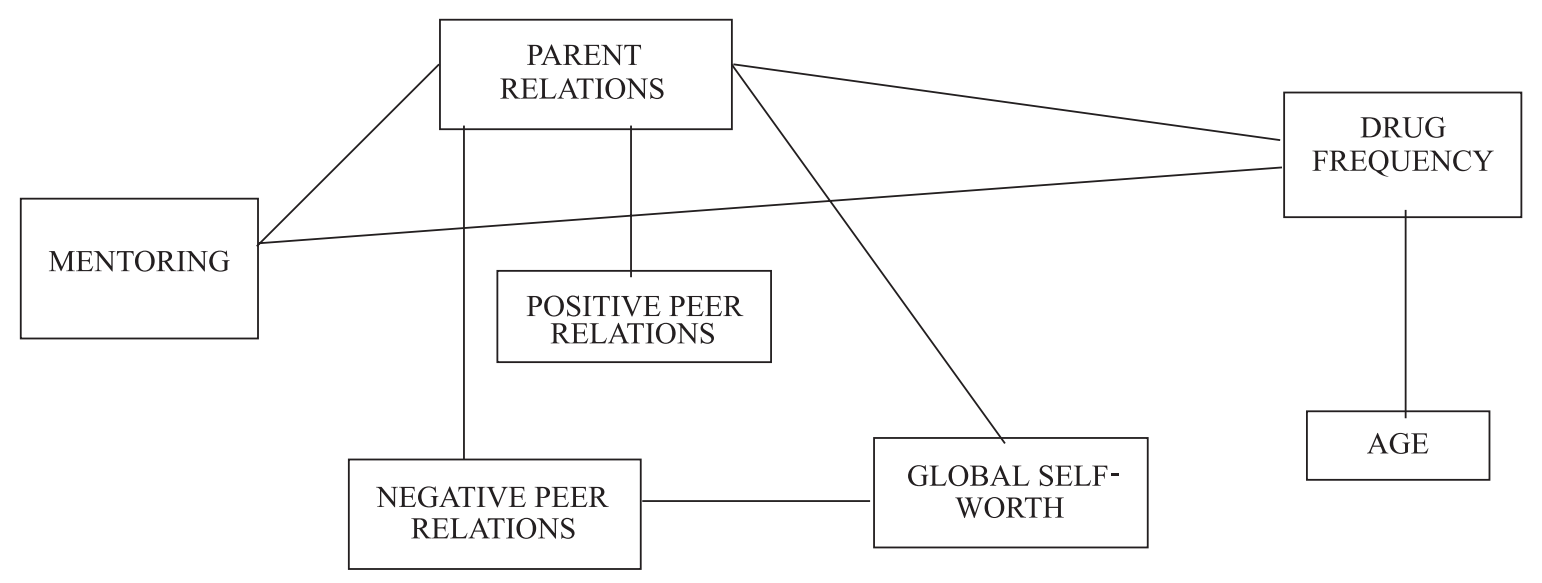

Figure 5. Graphic representation of significant pathways for the drug use model for youth matched for 12 months or more. Only the significant paths from the series of regression models are shown. Complete mediation was evidenced was present for the pathway between mentoring and drug use by parental relationships. The path between parental relation and self-worth was partially mediated by negative peer relations. 
parental relationships. This mediating effect is intriguing and deserves further consideration, as it may signify shifts in adolescents' basic orientation to relationships (Rhodes et al., 2000). The complex nature of this change process may also help to explain why the influence of mentoring on outcomes emerges over a relatively long period of time. The attenuated influence of shorter relationships may also relate to the vulnerabilities of at-risk adolescents to disappointment and rejection in response to terminations (Downey \& Feldman, 1996). In either case, the findings underscore the importance of sustained relationships in mentoring programs.

Although the model estimates for youth in long-term matches suggest these matches have more positive effects on youth, similar findings might have been observed if the youth who were particularly well-adjusted were also the youth most likely to remain in mentor relationships for 12 months or longer. If relationship duration is simply a proxy for better underlying adjustment, then improved parameter estimates in the longer lasting subsample may reflect unmeasured factors, such as better social skills or healthier psychological adjustment.

Although this possibility remains, it should be noted there were no baseline differences among the three groups (longer than 12 months, less than 12 months, controls) on any measures, including indexes of substance use, peer or parental relationships, or psychosocial adjustment. In addition, all baseline levels of the observed variables in the model were controlled. Nonetheless, additional research is needed to identify the factors that mediate sustained mentoring, including the attributes and motivations of youth and volunteers in longer term relationships.

Despite support for the conceptual model, several hypothesized pathways did not fall into predicted patterns. For example, there were no direct links between improved peer relationships and reduced substance use. This runs counter to our conceptual framework, which predicted that improved peer relationships would result in reductions in usage. It is possible that the quality of adolescents' relationships per se may be a less important than peer pressure in predicting substance use. Indeed, most previous research on the topic has found robust associations between peer pressure and drug use (Hawkins et al., 1992). In addition, the effects of improved peer relationships on substance may be complicated by the fact that closeness to deviant peers can heighten risk. In the absence of data on peers' substance use, it is difficult to decipher the conditions under which improved peer relationship constitutes a protective factor.

Our use of longitudinal data and structural equation modeling provided a sensitive test of the hypotheses and the large, national sample of adolescents lends confidence to the precision of the parameter es- timates and the generalizability of the findings. Although the $R^{2}$ values that emerged in the current models were relatively small, it should be noted that the majority of the adolescents in the study reported using neither drugs nor alcohol. Rather than attempting to explain substance use in the population, the primary purpose of this study was to examine the pathways of influence among mentoring, substance use, and other psychosocial variables. The difference in explained variance between the groups, compared to unmatched youth, appears to be indicative of the relatively stronger influence of longer lasting relationships and the corresponding differences in the pathways of influence.

Of course, the mentor relationships were all situated within the context of BBBS programs, where the degree of structure and the criteria for youth eligibility might limit the generalizability of the findings. It is also worth noting that the assessments were based solely on a relatively limited array of self-reports questionnaires and items. Future studies should supplement self-report with additional, more sensitive questionnaires as well as data from mentors, family members, and case managers. In addition, substance use was indexed in this study by single items of frequency, which may have constrained the reporting of substance use. Moreover, because youth in longer lasting relationships had a greater investment in maintaining a good impression with their mentors, they may have been less willing to report alcohol and drug use at posttest. If this were the case, then the positive associations that emerged in longer lasting dyads and reduced substance use may have been biased, at least in part, by socially desirable responses. It should be noted, however, that all interviews were conducted over the telephone by outside researchers who were trained to allow participants to adequately reflect on the material and to provide reassurances regarding the confidentiality of their responses. More generally, the self-reported rates that emerged in this study are comparable to rates reported elsewhere. For example, a national survey of eighth graders (roughly the age group and timeline of this study) revealed comparable 30-day prevalence rates of drinking (25.5\% nationally vs. $29 \%$ in this study) and drug use (10.9\% nationally vs. $9 \%$ in this study; Johnson et al., 2000). Nonetheless, future studies should consider including more in-depth assessment of drug and alcohol use and incorporating controls for social desirability. Within this context, measures of parent views of family processes and substance use values would provide more sensitive tests of our hypotheses regarding parental influences on peer choice and substance use (Farrell \& White, 1998; Fuligni \& Eccles, 1993). Finally, the somewhat skewed distributional patterns, although substantially corrected in the analyses, should lend some temperance to the conclusions. 
Despite these limitations, the findings that emerged from this study have both theoretical and practical applications. They concur with previous research on the beneficial role of adolescents' warm caring relationship with a nonparental adult but also extend the research to stress that these beneficial effects are mediated through improvements in the adolescent-parent relationship. They highlight the need for mentoring programs to recognize that interventions that enhance close relationships may have direct implications for positive outcomes. Program personnel should remain sensitive to this potential role of parental relationships and develop ways to capitalize on this function. More generally, the findings highlight the benefits of enduring mentoring interventions on adolescent substance use and underscore the importance of providing sufficient program resources to ensure relationship longevity. Although previous work focused largely on parent or peer influences, these findings highlight the influential role of nonparent adults on adolescent substance use.

\section{References}

Aiken, L. S., \& West, S. G. (1991). Multiple regression: Testing and interpreting interactions. Newbury Park, CA: Sage.

Andrews, J. A., Hops, H., Ary, D., Tildesey, E., \& Harris, J. (1993). Parental influences on early adolescent substance use: Specific and nonspecific effects. Journal of Early Adolescence, 13, 285-310.

Armsden, G. C., \& Greenberg, M. T. (1987). The Inventory of Parent and Peer Attachment (IPPA): Relationship to well being in adolescence. Journal of Youth and Adolescence, 16, 427-454.

Aseltine, R. H., Jr., Dupre, M., \& Lamlein, P. (2000). Mentoring as a drug prevention strategy: An evaluation of Across Ages. Adolescent \& Family Health, 1, 11-20.

Bahr, S. J., Marcos, A. C. \& Maughan, S. L. (1995). Family, educational and peer influences on the alcohol use of female and male adolescents. Journal of Studies on Alcohol, 56, 457-469.

Barnes, G. M. (1990). Adolescent alcohol and abuse and other problem behaviors: Their relationships and common parental influences. Journal of Youth and Adolescence, 13, 329-348.

Barnes, G. M., Farrell, M. P., \& Cairns, A. (1986). Parent socialization factors and adolescent drinking behaviors. Journal of Marriage and the Family, 48, 27-36.

Barnes, G. M., Farrell, M. P., \& Windle, M. (1990). Parent-adolescent interactions in the development of alcohol abuse and other deviant behaviors. In B. K. Barber \& B. C. Rollins (Eds.), Parent-adolescent relationships (pp. 121-140). Lanham, MD: University Press of America.

Baron, R. B., \& Kenny, D. A. (1986). The moderator-mediator variable distinction in social psychological research: Conceptual, strategic, and statistical considerations. Journal of Personality and Social Psychology, 51, 1173-1182.

Beier, S. R., Rosenfeld, W. D., Spitalny, K. C., Zanksy, S. M., \& Bontemmpo, A. N. (2000). The potential role of an adult mentor in influencing high-risk behaviors in adolescents. Archives of Pediatric Medicine, 154, 327-331.

Bell, N. J., Forthun, L. F., \& Sun, S. (2000). Attachment, adolescent competencies, and substance use: Developmental considerations in the study of risk behaviors. Substance Use and Misuse, $35,1177-1206$.
Berndt, T., \& Perry, B. (1986). Children's perceptions of friendships as supportive relationships. Developmental Psychology, 22, 640-648.

Bogenschneider, K., Wu, M., Raffaelli, M., \& Tsay, J. (1998). Parent influences on adolescent peer orientation and substance use: The interface of parenting practices and values. Child Development, 6, 1672-1688.

Bollen, K. A. (1989). Structural equations with latent variables. New York: Wiley.

Brady, K. T., \& Randall, C. L. (1999). Gender differences in substance use disorders. Psychiatric Clinics of North America, 22, 241-252.

Brook, J. S., Brook, D. W., Gordon, A. S., Whiteman, M., \& Cohen, P. (1986). Some models and mechanisms for explaining the impact of maternal and adolescent characteristics on adolescent stages of drug use. Developmental Psychology, 22, 460-467.

Brook, J. S., Whiteman, M., \& Gordon, A. S. (1982). Qualitative and quantitative aspects of adolescent drug use: Interplay of personality, family, and peer correlates. Psychological Reports, 51, 1151-1163.

Brook, J. S., Whiteman, M., Gordon, A. S., \& Brook, D. W. (1984). Parental determinants of female marijuana use. Developmental Psychology, 20, 1032-1043.

Chassin, L., Pillow, D. R., Curran, P. J., Molina, B. S. G., \& Barrera, M., Jr. (1993). Relation of parental alcoholism to early adolescent substance abuse: A test of three mediating mechanisms. Journal of Abnormal Psychology, 102, 3-19.

Chou, C. P., \& Bentler, P. M. (1995). Estimates and tests in structural equation modeling. In R. Hoyle (Ed.), Structural equation modeling: Issues and application (pp. 37-55). Newbury Park, CA: Sage.

Curran, P. J., Stice, E., \& Chassin, L. (1997). The relation between adolescent and peer alcohol use: A longitudinal random coefficients model. Journal of Consulting and Clinical Psychology, $65,130-140$

Curran, P. J., West, S. G., \& Finch, J. F. (1996). The robustness of test statistics to nonnormality and specification error in confirmatory factor analysis. Psychological Methods, 1, 16-29.

Darling, N., Hamilton, S. F., \& Niego, S. (1994). Adolescents' relations with adults outside the family. In R. Monemayor \& G. R. Adams (Eds.), Personal relationships during adolescence: Advances in adolescent development (pp. 216-235). Thousand Oaks, CA: Sage.

Davidson, W. S., \& Redner, R. (1988). The prevention of juvenile delinquency: Diversion from the juvenile justice system. In R. H. Price, E. L. Cowen, R. P. Lorion, \& J. Ramos-McKay (Eds.). Fourteen ounces of prevention: Theory, research, and prevention (pp. 123-137). New York: Pergamon.

Downey, G., \& Feldman, S.I. (1996). The implications of rejection sensitivityfor intimate relationships. Journal of Personality and Social Psychology, 70,1327-1343.

DuBois, D. L., Holloway, B. E., Cooper, H., \& Valentine, J. C. (2002). Effectiveness of mentoring programs for youth: A meta-analytic review. American Journal of Community Psychology.

Duncan, T. E., Duncan, S. C., \& Hops, H. (1994). The effects of family cohesiveness and peer encouragement on the development of adolescent alcohol use: A cohort-sequential approach to the analysis of longitudinal data. Journal of Studies on Alcohol, 55, 588-599.

Farrell, A. D., \& White, K. S. (1998). Peer influences and drug use among urban adolescents: Family structure and parent-adolescent relationship as protective factors. Journal of Consulting and Clinical Psychology, 2, 248-258.

Fuligni, A. J., \& Eccles, J. S. (1993). Perceived parental relationships and early adolescents' orientation toward peers. Developmental Psychology, 29, 622-632. 
Grossman, J. B. \& Rhodes, J. E. (2002). The test of time: Predictors and effects of duration in youth mentoring relationships. American Journal of Community Psychology.

Grossman, J. B., \& Tierney, J. P. (1998). Does mentoring work? An impact study of the Big Brothers/Big Sisters. Evaluation Review, 22, 403-426.

Hamilton, S. F., \& Darling, N. (1996). Mentors in adolescents' lives. In K. Hurrelmann \& S. F. Hamilton, (Eds.), Social problems and social contexts in adolescence: Perspectives across boundaries (pp. 121-142). New York: Aldine De Gruyter.

Harter, S. (1985). Manual for the Self-Perception Profile for Children. Denver, CO: University of Denver.

Hawkins, J. D., Catalano, R. F., \& Miller, M. Y. (1992). Risks and protective factors for alcohol and other drug problems in adolescence and early adulthood: Implications for substance use prevention. Psychological Bulletin, 112, 64-105.

Hu, L. T., Bentler, P. M., \& Kano, Y. (1992). Can test statistics in covariance structure analysis be trusted? Psychological Bulletin, 112, 351-362.

Hundleby, J. D., \& Mercer, G. W. (1987). Family and friends as social environments and their relationship to young adolescents' use of alcohol, tobacco, and marijuana. Journal of Marriage and the Family, 49, 151-164.

Jessor, R., \& Jessor, S. L. (1977). Problem behavior and psychological development: A longitudinal study of youth. New York: Academic.

Johnston, L. D., O'Malley, P. M., \& Bachman, J. G. (2003). The Monitoring the Future national survey results on adolescent drug use: Overview of key findings, 2002 (NIH Publication No. 00-4690). Rockville, MD: National Institute on Drug Abuse.

Jöreskog, K. G., \& Sörbom, D. (2000, February). Lisrel 8.30 and Prelis 2.30 [Computer software]. Lincolnwood, IL: Lawrence Erlbaum Associates, Inc.

Jöreskog, K. G., Sörbom, D., du Toit, S, \& du Toit, M. (1999). LISREL 8: New statistical features. Chicago: Scientific Software International.

Kandel, D. B. (1980). Developmental stages in adolescent drug involvement. In D. J. Lettiri, M. Sayers, and H. W. Pearson (Eds.) Theories on drug abuse: Selected contemporary perspectives. Rockville, MD: National Institute of Drug Abuse.

Kandel, D. B., \& Andrews, K. (1987). Processes of adolescent socialization by parents and peers. International Journal of the Addictions, 22, 319-342.

Kandel, D. B., \& Yamaguchi, K. (1999). Developmental stages of involvement in substance use. In P. J. Ott, R. E. Tarter, et al. (Eds.), Sourcebook on substance use: Etiology, epidemiology, assessment, and treatment (pp. 50-74). Boston: Allyn \& Bacon.

Kline, R. B. (1998). Principles and practice of structural equation modeling. New York: Guilford.

Li, F., Duncan, T. E., \& Hyman, H. (2001). Examining developmental trajectories in adolescent alcohol use using piecewise growth mixture modeling analysis. Journal of Studies on Alcohol, 62, 199-210.

LoSciuto, L., Rajala, A. K., Townsend, T. N., \& Taylor, A. S. (1996). An outcome evaluation of Across Ages: An intergenerational mentoring approach to drug prevention. Journal of Adolescent Research, 11, 116-129.

Mason, W. A., \& Windle, M. (2001). Family, religious, school, and peer influences on adolescent alcohol use: A longitudinal study. Journal of Studies on Alcohol, 62, 44-53.

McPartland, J. M., \& Nettles, S. M. (1991). Using community adults as advocates or mentors for at-risk middle school students: A two-year evaluation of project RAISE. American Journal of Education, 99, 568-586.

Miller, L. D. (1994). Adolescents, self-esteem and substance use. In J. A. Lewis, et al. (Eds.), Additions: Concepts and strategies for treatment (pp. 349-357). Gaithersburg, MD: Aspen.
Newcomb, M. D., \& Bentler, P. M. (1986). Frequency and sequence of drug use: A longitudinal study from early adolescence to young adulthood. Journal of Drug Education, 16, 101-120

Oetting, E. R., \& Beauvais, F. (1986). Peer cluster theory: Drugs and the adolescent. Journal of Counseling and Development, 65, $17-22$.

Olds, D., Kitzman, H., Cole, R., \& Robinson, J. (1997). Theoretical formulations of a program of home visitation for pregnant women and parents of young children. Journal of Community Psychology, 25, 9-26.

O'Malley, P. M., Johnston, L. D., \& Bachman, J. G. (1998). Alcohol use among adolescents. Alcohol Health and Research World, $22,85-93$.

Patterson, G. R., Reid, J. B., \& Dishion, T. J. (1992). Anitsocial boys. Eugene, OR: Castalia.

Petraitis, J., Flay, B. R., \& Miller, T. Q. (1995). Reviewing theories of adolescent substance use: Organizing pieces in the puzzle. Psychological Bulletin, 117, 67-86.

Rhodes, J. E. (2002). Stand by me. The risks and rewards of mentoring today's youth. Cambridge: Harvard University Press.

Rhodes, J. E., Gingiss, P. L., \& Smith, P. B. (1994). Risk and protective factors for alcohol use among pregnant African American, Hispanic, and White adolescents: The influence of peers, sexual partners, family members, and mentors. Addictive Behaviors, $19,555-564$.

Rhodes, J. E., Grossman, J. B., \& Resch, N. (2000). Agents of change: Pathways through which mentors influence adolescents' academic adjustment. Child Development, 71, $1662-1671$.

Rhodes, J. E., Haight, W. L., \& Briggs, E. (1999). The influence of mentoring on the peer relationships of foster youth in relative and nonrelative care. Journal of Research on Adolescence, 9 , 185-201.

Richter, S. S., Brown, S. A., \& Mott, M. A. (1992). The impact of social support and self-esteem on adolescent substance use treatment outcomes. Journal of Substance Use, 2, 371-385.

Ringwalt, C. L., Graham, L. A., Paschall, M. J., Flewelling, R. L., \& Browne, D. C. (1996). Supporting adolescents with guidance and employment (SAGE). American Journal of Preventive Medicine, 12, 31-38.

Sampson, R. J., \& Laub, J. H. (1994). Urban poverty and the family context of delinquency: A new look at structure and process in a classic study. Child Development, 65, 523-540.

Satorra, A., \& Bentler, P. M. (1988). Scaling correlations for chi-square statistics in covariance structure analysis. Proceedings of the Business and Economic Statistics Section of the American Statistical Association, 308-313.

Schulenberg, J., Maggs, J. L., Dielman, T. E., Leech, S. L., Kloska, D. D., Shope, J. T., et al. (1999). On peer influences to get drunk: A panel study of young adolescents. Merrill-Palmer Quarterly, 45, 108-142.

Steiger, J. H. (1990). Structural model evaluation and modification: An interval estimation approach. Multivariate Behavioral Research, 25, 173-180.

Steinberg, L. (2001). We know some things: Adolescent-parent relationships in retrospect and prospect. Journal of Research on Adolescence, 11, 1-20.

Tabachnick, B. G., \& Fidell, L. S. (1996). Using multivariate statistics (3rd ed.). New York: HarperCollins.

Taylor, A. S., LoSciuto, L., Fox, M., Hilbert, S. M., \& Sonkowsky, M. (1999). The mentoring factor. Evaluation of the across ages' intergenerational approach to drug use prevention. Child and Youth Services, 20, 77-99.

Tierney, J. P., Grossman, J. B., \& Resch, N. L. (1995). Making a difference: An impact study of Big Brothers/Big Sisters. Philadelphia: Public/Private Ventures. 
Weinberg, N. A., Rahdert, E., Colliver, J. D, \& Glantz, M. D. (1998), Adolescent substance abuse: A review of the past 10 years. Journal of the American Academy of Child and Adolescent Psychiatry, 37, 252-261.

West, S. G., Finch, J. F., \& Curran, P. J. (1995). Structural equation models with nonnormal variables. In R. Hoyle (Ed.), Structural equation modeling: Concepts, issues, and applications (pp. 56-75). Thousand Oaks, CA: Sage.
Zimmerman, M. A., \& Schmeelk-Cone, K. H. (2003). A longitudinal analysis of adolescent substance use and school motivation among African American youth. Journal of Research on Adolescence, 13, 185-210.

Received November 12, 2003

Final revision received June 7, 2004

Accepted June 11, 2004 